\title{
DRUGS AND WAR-TIME ALTERNATIVES
}

$\mathrm{F}^{\mathrm{o}}$ OR the guidance of general practitioners, hospitals and drug manufacturing houses, an official committee composed of recognized medical authorities, acting under departmental ægis, has compiled a list of drugs the importation of which is considered unnecessary. It is suggested that drugs on this list should be used with the strictest economy while the War continues. The purpose of this recommendation is to support the Government policy to cease using cargo space and foreign currency to import drugs which are not essential in war-time or for which substitutes can be obtained at home.

The official committee suggests substitutes which are considered suitable for some of the drugs included in the list. Instead of aconite, it is suggested that benzocaine should be used for local application; since the sources of aconite are Germany, Switzerland and France, importation is not possible. The note against Balsam of Tolu (a South American product) is that no substitute is necessary. With regard to buchu leaves, cubebs, balsam cophiba and sandalwood oil, it is suggested that one or other of the following substitutes should be used: sulphanilamide, hexamine, mandelic acid, sodium benzoate, scoparium. In place of the Mozambique drug, calumba root, the use of quassia is indicated. As a substitute for cantharides, the sources of which are Spain, Russia, Hungary and China, mustard is suggested.

Small production of English caraway seed is avail- able ; in the past our main supplies have come from Holland or Germany; home production should be encouraged but, in the meantime, aniseed is suggested as a substitute. The importation of cassia from China is unnecessary. Instead of coriander seed, derived mainly from Morocco and Russia, the use of cardamons is proposed, supplies being plentiful. Male fern and carbon tetrachloride are suggested as substitutes for cusso. The therapeutic value of fig is said to be doubtful.

Synthetic analgesies are recommended to replace gelsemium, an American importation. Another American drug, hamamelis, might be replaced by tannic acid. Instead of Mexican jalap and its resin, the use of colocynth, stocks of which are of fair size, is proposed. Tannic acid is suggested in place of krameria, and kaolin in place of linseed for poultices. Lobelia herb, which comes from the eastern United States, may be replaced by nikethamide or leptazol, or by stramonium, should the home-produced drug be available. As substitutes for pelletierine tannate, which is derived from Mediterranean countries, male fern and carbon tetrachloride are recommended. Indian podophyllum is suggested instead of the American root, and isphagula instead of psyllium seed. Salicin may be replaced by sodium salicylate, scammony by Indian podophyllum and senega root by iodides, ammonium bicarbonate and ammonium chloride.

\section{PROGRESS IN SEISMOLOGY}

$\mathrm{T}$ HE forty-fifth report of the British Association committee on seismological investigations was to have been presented at the meeting to have been held at Reading. This meeting was cancelled, but the report in question is now in print.

In spite of the War, seismology has made progress in Great Britain during the year. The committee has Milne-Shaw seismographs on loan at Oxford (2), Cape Town (2), Edinburgh and Perth (West Australia). All these are in operation, except one at Oxford. There is also a Jagger shock recorder in operation at Comrie. The seismograph (Milne-Shaw No. 63) and seconds regulator clock sent to Fiji last year have not yet been erected. They are awaiting the construction of the projected meteorological station at Suva, which will most likely be a matter of only a few months. A complete new recording outfit supplied with two motors and drums, one spring-driven and the other with an electric drive, has been sent to Entebbe. The original recording units sent out in 1923 have also been overhauled and repaired in West Bromwich and returned. New mirrors have been sent to several Indian stations.

Miss E. F. Bellamy is carrying on with the work at Oxford with the part-time assistance of $\mathrm{Mr}$. Cook, in the absence of Mr. J. S. Hughes and Prof. H. H. Plaskett. The old system of co-ordinates has been used in the preparation of the International Seismological Summary, since no decision was taken at Washington last September on the adoption of geocentric co-ordinates. Very little material is now being received for the Summary. Last September the Milne-Shaw N-S seismograph at Oxford was dismantled and stored for safety, the seismological basement being well shored up and protected. During the year, Mr. R. E. Ockenden has again made a valuable gift to the John Milne Library, and the British Association Seismological Committee has been responsible for publishing new seismological tables by Dr. H. Jeffreys and Dr. K. E. Bullen.

The Accra earthquake of June 22, 1939, has been investigated, all the macroseismic work being conducted by the Geological Survey of the Gold Coast under the direction of Dr. N. R. Junner. The focus was found to have been below a very steep slope in the bed of the ocean to the south of Accra, and it is hoped that full details will be published in due course.

Dr. A. T. Dollar is continuing the work on British earthquakes from the Geology Department of the University of Glasgow. Further matter has been obtained for the catalogue of British earthquakes for the period January 1, 1916-October 1, 1935, and 27 more permanent voluntary observers have been added to the 321 previously on the list, though Channel Islands observers have been lost owing to evacuation. Since July 1, 1939, the following British earthquakes have been investigated: July 18, 1939, Manchester ; February 2-3, 1940, Stirling; March 18, 1940, Birmingham; and a mine shake, July 5, 1939, Bargoed, Glamorgan. Information is now being collected concerning the earthquakes of July 9, 1940, North Argyllshire, July 14-15, 1940, West Midlands, and July 16, 1940, Stirlingshire. 